\title{
Pembinaan Kriya, Fotografi, Videografi, dan Karawitan di Desa Sendangsari, Pengasih, Kabupaten Kulon Progo
}

\author{
Budi Hartono ${ }^{1,}$, Oscar Samaratungga ${ }^{2}$ \\ ${ }^{1}$ Program Studi Kriya Seni, Fakultas Seni Rupa \\ ${ }^{2}$ Program Studi Fotografi, Fakultas Media Rekam \\ Institut Seni Indonesia Yogyakarta \\ Jalan Parangtritis Km 6,5, Sewon, Bantul, Daerah Istimewa Yogyakarta 55188 \\ No. Hp.: ${ }^{1} 081227744493,{ }^{20} 082225035294$ \\ E-mail : 'baworbudi@gmail.com; ${ }^{2}$ oscar.keken@gmail.com
}




\title{
Pembinaan Kriya, Fotografi, Videografi, dan Karawitan di Desa Sendangsari, Pengasih, Kabupaten Kulon Progo
}

\author{
Budi Hartono ${ }^{1}$, Oscar Samaratungga ${ }^{2}$ \\ ${ }^{1}$ Program Studi Kriya Seni, Fakultas Seni Rupa \\ ${ }^{2}$ Program Studi Fotografi, Fakultas Media Rekam \\ Institut Seni Indonesia Yogyakarta \\ Jalan Parangtritis Km 6,5, Sewon, Bantul, Daerah Istimewa Yogyakarta 55188 \\ No. Hp.: ${ }^{10} 081227744493,{ }^{20} 082225035294$ \\ E-mail : 'baworbudi@gmail.com; ${ }^{2}$ oscar.keken@gmail.com
}

\begin{abstract}
Abstrak
Pembinaan Kriya, Fotografi, Videografi, dan Karawitan di Desa Sendangsari, Pengasih, Kabupaten Kulonprogo merupakan bagian dari Program Pengembangan dan Pembinaan Wilayah Seni (P3Wilsen) ISI Yogyakarta. Kegiatan ini melibatkan dosen dan juga mahasiswa ISI Yogyakarta yang diterjunkan langsung di tengah masyarakat untuk melakukan pengembangan dan pembinaan seni yang ada dan dibutuhkan oleh masyarakat, komunitas, dan UKM. Beberapa pendekatan yang dilakukan untuk program ini adalah community development, yaitu pendekatan yang berorientasi pada upayaupaya pengembangan pemberdayaan masyarakat dengan menjadikan masyarakat sebagai subjek dan sekaligus objek pembangunan dan melibatkan mereka secara langsung dalam berbagai kegiatan pengabdian masyarakat sebagai upaya meningkatkan peran serta mereka dalam pembangunan demi kepentingan mereka sendiri. Partisipatif, yaitu pendekatan yang berorientasi kepada upaya peningkatan peran serta masyarakat secara langsung dalam berbagai proses dan pelaksanaan pengabdian. Dengan partisipasi dan keterlibatan masyarakat secara langsung, dampak dan manfaat dapat dirasakan oleh masyarakat langsung terutama dalam meningkatkan kualitas sumber daya manusia dan kesejahteraan masyarakat.
\end{abstract}

Kata kunci: pembinaan, kriya, fotografi, videografi, karawitan

Wood Craft, Videography, and Karawitan Coaching in Sendangsari Village, Pengasih, Kulon Progo Regency

\begin{abstract}
Wood Craft, Videography, and Karawitan (Javanese instrument playing) Development in Sendangsari Village, Pengasih, Kulon Progo Regency is part of ISI Yogyakarta's Art Area Development and Coaching Program (P3Wilsen). The activity comprises of ISI Yogyakarta lecturers and students, deployed directly in the community to develop and coach the existing arts which are needed by the local, community, and SMEs. One of the approaches taken for this program is Community Development, an approach oriented to community empowerment development, with the community as both subject and object of this development and being directly involved in various services as an effort to improve their well-being. Another approach used is being participative, oriented to the improvement of society's contribution through various process and service. With the direct participation, it is hoped that the community can experience the immediate effect in the increase of human resources as well as welfare.
\end{abstract}

Keywords: coaching, craft, photography, videography, karawitan 


\section{PENDAHULUAN}

Kelurahan Sendangsari terletak di Kecamatan Pengasih, Kabupaten Kulon Progo. Desa Sendangsari memiliki pemandangan alam yang memikat. Dahulu di Desa Sendangsari terdapat pemandian Clereng yang airnya sangat jernih. Masyarakat sering menggunakannya karena selain alami, juga banyak ikan yang menambah keindahan pemandian Clereng. Seiring perkembangan waktu, pemandian Clereng kini difungsikan untuk sumber air PDAM sehingga sumber air Clereng yang terkenal jernih dan banyak ikannya sekarang tinggal kenangan. Sekarang terdapat kolam renang walaupun tidak alami seperti dahulu lagi.

Pada tahun 2017 Desa Sendangsari mengadakan Gelar Pentas Budaya. Kesenian yang ditampilkan antara lain kesenian jathilan, gejog lesung, dan kethoprak guyon maton. Tujuan diadakan acara tersebut ialah memotivasi penduduk setempat, khususnya, baik tua maupun muda, dan masyarakat Kulon Progo pada umumnya, untuk mencintai dan merawat seni budaya lokal. Desa Sendangsari memiliki sepuluh pedukuhan, dengan potensi kesenian yang berbeda-beda. Misalnya, Pedukuhan Paingan memiliki potensi kethoprak yang sudah cukup terkenal di Kabupaten Kulon Progo. Potensi lainnya adalah tari angguk. Tari angguk merupakan kesenian khas Kabupaten Kulon Progo yang memiliki pesona kuat karena seluruh penarinya ialah perempuan dengan riasan dan kostum yang unik.

Di Desa Sendangsari terdapat kerajinan tatah sungging kulit dan kerajinan sabut kelapa. Produk kerajinan sabut kelapa yang dihasilkan antara lain sapu, keset, dan matras. Di samping itu, di sana juga terdapat komunitas fotografi dan videografi. Dalam program Pengembangan dan Pembinaan Wilayah Seni yang diselenggarakan oleh ISI Yogyakarta tahun 2020, diadakan pelatihan-pelatihan di Desa
Sendangsari. Adapun pelatihan tersebut meliputi perancangan produk, diversifikasi produk, pengayaan desain, dan pembuatan suvenir khas daerah setempat. Tujuannya ialah untuk mempertahankan keberlangsungan usaha dan lebih jauh lagi dapat mengembangkan usahanya dengan membuat komoditas baru selain wayang kulit, misalnya membuat perlengkapan dekorasi rumah. Semangat tersebut muncul setelah Kabupaten Kulon Progo mulai memperkenalkan pengembangan beberapa sektor ekonomi yang memicu tumbuhnya kebutuhan-kebutuhan baru bagi masyarakat. Menyandang predikat sebagai Desa Budaya, Desa Sendangsari tentunya mempunyai komunitas-komunitas anak muda yang kreatif, seperti komunitas fotografi dan videografi. Komunitas tersebut memiliki peran penting dalam mendokumentasikan semua pertunjukan seni yang diadakan di Desa Sendangsari. Tentunya hal tersebut juga menambah koleksi dokumentasi kegiatan desa. Untuk meningkatkan kemampuan komunitas tersebut, diadakan pelatihan fotografi dan videografi. Manfaat yang diperoleh dari pelatihan tersebut juga akan dirasakan oleh Desa Sendangsari karena dokumentasi yang dihasilkan oleh komunitas itu dapat menambah koleksi dokumentasi potensi desa, yang juga dapat digunakan untuk sarana promosi Desa Sendangsari. Desa Sendangsari juga mempunyai tim Sistem Informasi Desa (SKD), yaitu merupakan tim yang bertugas untuk memberikan informasi seluruh kegiatan dan potensi unggul yang dimiliki oleh Desa Sendangsari melalui media sosial. Dengan demikian, dengan adanya pembinaan dan pelatihan dokumentasi fotografi dan videografi sangat membantu tim SKD untuk lebih mematangkan dasar-dasar dokumentasi fotografi dan videografi.

Masyarakat Desa Sendangsari sebagian besar mengandalkan pertanian dan hasil bumi sebagai mata pencaharian. Hasil bumi mereka 
dipasarkan di desa dan kota. Mata pencaharian lainnya ialah menjadi pengrajin produk dari sabut kelapa dan pengrajin tatah kulit sungging. Produk kerajinan di desa ini memerlukan sentuhan tangan-tangan kreatif agar mampu bersaing dengan produk sejenis. Dari latar belakang tersebut, dapat diambil kesimpulan antara lain:

1. Pengenalan dan pelatihan desain cenderamata atau suvenir khas daerah yang merespons sumber produk ataupun material yang sudah ada di Desa Sendangsari.

2. Pelatihan-pelatihan tentang pendampingan kerajinan yang diselenggarakan oleh pemerintah ataupun pihak lain masih terbatas frekuensinya. Kesempatan untuk mengikuti kegiatan pelatihan-pelatihan menjadi belum maksimal, padahal mereka sangat membutuhkan tambahan pengetahuan dan keterampilan untuk mewujudkan harapan mereka.

3. Pelatihan dokumentasi fotografi dan videografi. Pelatihan ini tidak hanya menggunakan kamera DSLR, tetapi juga menggunakan alat yang lebih sederhana seperti telepon cerdas atau smartphone. Kemajuan teknologi kamera dalam telepon seluler sudah sangat mencukupi untuk sebuah dokumentasi foto dan video kegiatan ataupun produk barang kerajinan. Akan tetapi, baik di tim SKD maupun komunitas masyarakat selama ini belajar secara otodidak dan mendapat informasi dari media sosial sehingga hasilnya belum maksimal.

4. Masyarakat belum memiliki kelembagaan komunitas kreatif ataupun kesenian yang diperlukan untuk menjaga keberlanjutan kegiatan seni. Selama ini kegiatan mereka tidak ada keberlanjutannya karena kurang adanya tata kelola yang pas di masyarakat.
Menanggapi permasalahan seperti yang tersebut di atas, diadakanlah pendampingan seni bersama enam orang mahasiswa ISI Yogyakarta. Keenam mahasiswa tersebut terdiri atas dua orang mahasiswa Program Studi Kriya minat utama kulit, yang menitikberatkan pada proses desain dan diversifikasi produk serta kreativitas para anggota kelompok dalam berkarya; dua orang mahasiswa Program Studi Fotografi dan Televisi; dua orang mahasiswa Program Studi Karawitan. Pendampingan yang dilakukan bertitik tolak dari pengetahuan dan keterampilan yang telah dimiliki oleh para pelaku seni, yaitu meningkatkan pengetahuan dan keterampilan di bidang seni tatah sungging, fotografi, videografi, serta seni karawitan, dengan menitikberatkan proses desain dan diversifikasi produk serta kreativitas para anggota kelompok dalam berkarya. Adapun materi yang diberikan dalam pelatihan bersifat teoretis dan praktik yang mencakup:

a. wawasan dan pengetahuan tentang suvenir, cenderamata, yang meliputi desain dan praktik serta membuat produk jadi berbahan kulit, misalnya suvenir atau produk lainnya;

b. wawasan dan pengetahuan tentang proses pendokumentasian, meliputi teknik fotografi dan televisi;

c. pengetahuan karawitan meliputi teori dan praktik tabuhan instrumen seni karawitan.

Pelatihan mengacu Sjaifudian, Haryadi, \& Maspiyati (1995) bahwa perlu disesuaikan dengan rencana strategis untuk pengembangan usaha kecil yang mengidentifikasi isu lingkungan.

Tujuan diadakannya pengembangan seni melalui P3Wilsen ini adalah: (1) meningkatkan pengetahuan, kemampuan, dan keterampilan, baik secara pengetahuan berupa wawasan, pemahaman teknis, maupun pragmatis pelaku seni; dan (2) mendorong para 
anggota agar memiliki kemampuan dan motivasi dalam rangka pengembangan bidang keterampilan dan kewirausahaan.

Manfaat yang diperoleh dari program pengembangan seni tersebut adalah sebagai berikut.

1. Para pelaku seni mendapat pengetahuan sekaligus pengalaman, khususnya di bidang kriya kulit, fotografi, videografi, dan karawitan sehingga diharapkan daya kreativitas mereka meningkat serta terasah dengan baik dan ke depannya dapat merintis usaha secara mandiri.

2. Bagi pemerintah daerah, khususnya di wilayah Desa Sendangsari, kemampuan yang telah diperoleh pelaku seni, akan dapat turut ambil bagian dalam mengisi kegiatan dengan menghasilkan karya yang memiliki dampak ekonomis yang berkaitan dengan bidang kepariwisataan.

3. Bagi perguruan tinggi penyelenggara, dapat terjalin hubungan kerja sama antara pihak Lembaga Pengabdian Masyarakat ISI Yogyakarta dan para pelaku seni serta instansi yang terkait di wilayah ini melalui program P3Wilsen sebagai wujud pelaksanaan Tridarma Perguruan Tinggi.

4. Bagi masyarakat di Desa Sendangsari, dapat meningkatkan apresiasi terhadap kesenian lokal, untuk ikut peduli menjaga, melestarikan, dan mengembangkan warisan budaya adiluhung.

\section{METODE PENGABDIAN}

A. Objek Pembinaan

Pelaksanaan pembinaan dalam program P3Wilsen ditujukan kepada para seniman yang tergabung dalam beberapa kelompok kesenian seperti berikut:

a. Grup Karawitan Bapak-Bapak di Balai

Desa Sendangsari, b. Grup Karawitan Remaja di Balai Desa Sendangsari,

c. Grup Karawitan Ibu PKK Desa Sendangsari,

d. Grup SID dan remaja-remaja komunitas fotografi dan videografi di Desa Sendangsari,

e. Kelompok usaha kerajinan sabut kelapa di Desa Sendangsari, dan

f. Kelompok usaha kerajinan kulit di Desa Sendangsari.

Dengan demikian, para seniman dan masyarakat yang terlibat dalam program P3Wilsen cukup beragam, sesuai dengan bakat dan kemampuan dalam bidang seninya masing-masing.

Pada dasarnya sebagai tempat kegiatan dalam program P3Wilsen berada di beberapa tempat, dengan berbagai jenis seni menurut sanggar seninya masing-masing yang berada di wilayah Desa Sendangsari. Untuk mengetahui tempat-tempat pelatihan sanggar seni dan kelompok usaha adalah seperti berikut:

a. Balai Desa Sendangsari sebagai pusat kegiatan pembinaan P3Wilsen dan

b. hunting foto dan pelatihan video di beberapa tempat wisata di Desa Sendangsari.

Kegiatan pembinaan ini dilaksanakan dalam kurun waktu mulai 28 Oktober sampai dengan 21 November 2020. Pertemuan dengan instruktur sebanyak enam kali dan selama dua belas hari didampingi oleh mahasiswa yang diikutsertakan dalam kegiatan ini. Jadwal pertemuan ditentukan berdasarkan kesepakatan antara instruktur dan mahasiswa dengan peserta. Alokasi waktu, jadwal, dan materi kegiatan disajikan dalam tabel berikut ini. 
Jadwal Kegiatan

\begin{tabular}{|c|c|c|}
\hline Waktu & Materi & Tempat \\
\hline \multirow[t]{3}{*}{ Minggu I } & Penerjunan P3Wilsen & $\begin{array}{l}\text { Balai Desa } \\
\text { Sendang Sari }\end{array}$ \\
\hline & $\begin{array}{l}\text { Pertemuan dengan masyarakat (peserta } \\
\text { pelatihan) }\end{array}$ & Rumah salah satu pelaku kesenian \\
\hline & Penyusunan jadwal kegiatan & Aula Balai Desa Sendang Sari \\
\hline Minggu II & $\begin{array}{l}\text { Pelatihan: } \\
\text { 1. Dasar-dasar seni fotografi dan videografi } \\
\text { 2. Dasar-dasar desain produk/suvenir } \\
\text { 3. Dasar-dasar teknik karawitan dan } \\
\text { pengenalan instrumen }\end{array}$ & $\begin{array}{l}\text { Tempat pelatihan masing-masing } \\
\text { 1. Aula Balai Desa Sendang Sari } \\
\text { 2. Ruang Kerajinan } \\
\text { 3. Ruang Karawitan }\end{array}$ \\
\hline Minggu III & $\begin{array}{l}\text { Pelatihan: } \\
\text { 1. Pengembangan seni } \\
\text { fotografi/videografi } \\
\text { 2. Proses pembuatan wayang dari barang } \\
\text { bekas } \\
\text { 3. Pengenalan bentuk gendhing }\end{array}$ & $\begin{array}{l}\text { Tempat pelatihan masing-masing } \\
\text { 1. Aula Balai Desa sendang Sari } \\
\text { 2. Ruang Kerajinan } \\
\text { 3. Ruang Karawitan }\end{array}$ \\
\hline \multirow[t]{4}{*}{ Minggu IV } & Pelatihan kewirausahaan & Tempat pelatihan masing-masing \\
\hline & Pelatihan manajemen & Tempat pelatihan masing-masing \\
\hline & $\begin{array}{l}\text { Ekspos: } \\
\text { 1. Hunting ke Pabrik Jamu } \\
\text { 2. Pemanfaatan limbah sabut kelapa } \\
\text { menjadi suvenir } \\
\text { 3. Pratik lancaran Sluku Sluku Bathok }\end{array}$ & $\begin{array}{l}\text { Pabrik Jamu Naturindo } \\
\text { Tempat pelatihan masing-masing } \\
\text { Tempat pelatihan masing-masing }\end{array}$ \\
\hline & $\begin{array}{l}\text { Penutupan dan Penarikan mahasiswa } \\
\text { P3Wilsen }\end{array}$ & Kantor Kecamatan \\
\hline Minggu V & $\begin{array}{l}\text { Ekspos: } \\
\text { 1. Hunting di sekitar }\end{array}$ & \\
\hline
\end{tabular}

Materi Pembinaan

\begin{tabular}{|c|c|c|c|c|}
\hline Bidang Kegiatan & & ○ Materi & & O Metode \\
\hline $\begin{array}{l}\text { Dasar-dasar Seni } \\
\text { Pertunjukan }\end{array}$ & O & $\begin{array}{l}\text { Pengenalan dasar-dasar } \\
\text { pertunjukan } \\
\text { Inovasi Seni fotografi/ } \\
\text { televisi } \\
\text { Inovasi Seni Karawitan }\end{array}$ & $\begin{array}{l}0 \\
0 \\
0\end{array}$ & $\begin{array}{l}\text { Ceramah } \\
\text { Praktik } \\
\text { Diskusi }\end{array}$ \\
\hline $\begin{array}{l}\text { Pengembangan Seni } \\
\text { Pertunjukan }\end{array}$ & O & $\begin{array}{l}\text { Pengenalan jenis alat dan } \\
\text { properti seni } \\
\text { pertunjukan }\end{array}$ & $\begin{array}{l}0 \\
0 \\
0\end{array}$ & $\begin{array}{l}\text { Ceramah } \\
\text { Praktik } \\
\text { Diskusi }\end{array}$ \\
\hline
\end{tabular}




\begin{tabular}{|c|c|c|c|c|}
\hline & $\begin{array}{l}0 \\
0 \\
0\end{array}$ & $\begin{array}{l}\text { Pengenalan komposisi } \\
\text { Pengenalan improvisasi } \\
\text { Teknik pementasan }\end{array}$ & & \\
\hline Kewirausahaan & $\begin{array}{l}0 \\
0 \\
0\end{array}$ & $\begin{array}{l}\text { Pengenalan bentuk- } \\
\text { bentuk sanggar } \\
\text { Foundraising } \\
\text { Promosi }\end{array}$ & 0 & $\begin{array}{l}\text { Ceramah } \\
\text { Praktik } \\
\text { Diskusi }\end{array}$ \\
\hline Manajemen & $\begin{array}{l}0 \\
0 \\
0 \\
0\end{array}$ & $\begin{array}{l}\text { Manajemen Produksi } \\
\text { Manajemen Pemasaran } \\
\text { Manajemen SDM } \\
\text { Manajemen Keuangan }\end{array}$ & 0 & $\begin{array}{l}\text { Ceramah } \\
\text { Praktik } \\
\text { Diskusi }\end{array}$ \\
\hline
\end{tabular}

\begin{tabular}{|c|c|c|c|c|}
\hline $\begin{array}{c}\text { Bidang } \\
\text { Kegiatan }\end{array}$ & & ○ Materi & & o Metode \\
\hline $\begin{array}{l}\text { Dasar-dasar Seni } \\
\text { Rupa }\end{array}$ & O & $\begin{array}{l}\text { Pengenalan dasar-dasar } \\
\text { seni rupa } \\
\text { Inovasi untuk } \\
\text { pengembangan produk } \\
\text { kulit dan sabut kelapa } \\
\text { Pengenalan alat dan } \\
\text { bahan bahan dasar }\end{array}$ & O & $\begin{array}{l}\text { Ceramah } \\
\text { Praktik } \\
\text { Diskusi }\end{array}$ \\
\hline $\begin{array}{l}\text { Pengembangan } \\
\text { Seni Rupa }\end{array}$ & O & $\begin{array}{l}\text { Pengenalan jenis alat dan } \\
\text { bahan pembuatan produk } \\
\text { kulit dan sabut kelapa } \\
\text { Pengenalan komposisi } \\
\text { kulit dan sabut kelapa } \\
\text { Pengenalan improvisasi } \\
\text { ide pembuatan kerajinan } \\
\text { kulit dan sabut kelapa } \\
\text { Teknik pembuatan dan } \\
\text { pengerjaan kulit, sabut } \\
\text { kelapa }\end{array}$ & $\begin{array}{l}0 \\
0\end{array}$ & $\begin{array}{l}\text { Ceramah } \\
\text { Praktik } \\
\text { Diskusi }\end{array}$ \\
\hline Kewirausahaan & O & $\begin{array}{l}\text { Pengenalan dan cara } \\
\text { pemasaran } \\
\text { Foundraising } \\
\text { Promosi }\end{array}$ & ○ & $\begin{array}{l}\text { Ceramah } \\
\text { Praktik } \\
\text { Diskusi }\end{array}$ \\
\hline Manajemen & 0 & $\begin{array}{l}\text { Manajemen Produksi } \\
\text { Manajemen Pemasaran } \\
\text { Manajemen SDM di Desa } \\
\text { Sendangsari } \\
\text { Manajemen Keuangan }\end{array}$ & O & $\begin{array}{l}\text { Ceramah } \\
\text { Praktik } \\
\text { Diskusi }\end{array}$ \\
\hline
\end{tabular}




\begin{tabular}{|c|c|c|c|}
\hline \multicolumn{2}{|c|}{ Bidang Kegiatan } & Materi & Metode \\
\hline \multicolumn{2}{|c|}{$\begin{array}{l}\text { Dasar-dasar Seni Media } \\
\text { Rekam }\end{array}$} & $\begin{array}{l}\text { - Pengenalan dasar-dasar } \\
\text { Fotografi } \\
\text { - Inovasi Seni fotografi/ } \\
\text { Videografi }\end{array}$ & $\begin{array}{l}\text { - } \text { Ceramah } \\
\text { - Praktik } \\
\text { - Diskusi }\end{array}$ \\
\hline \multicolumn{2}{|c|}{$\begin{array}{l}\text { Pengembangan Seni } \\
\text { Pertunjukan }\end{array}$} & $\begin{array}{l}\text { - Pengenalan jenis alat dan } \\
\text { properti seni media rekam } \\
\text { - Pengenalan komposisi dasar- } \\
\text { dasar fotografi dan videografi } \\
\text { - Pengenalan improvisasi dasar } \\
\text { penceritaan dan konten, teknik } \\
\text { angel kamera, teknik editing. } \\
\text { - Teknik eksekusi fotografi dan } \\
\text { videografi }\end{array}$ & $\begin{array}{l}\text { - Ceramah } \\
\text { - Praktik } \\
\text { - Diskusi }\end{array}$ \\
\hline \multicolumn{2}{|c|}{ Kewirausahaan } & $\begin{array}{l}\text { - Pengenalan bentuk-bentuk foto } \\
\text { produk dan video } \\
\text { - Foundraising } \\
\text { - Promosi }\end{array}$ & $\begin{array}{l}\text { - Ceramah } \\
\text { - Praktik } \\
\text { - Diskusi }\end{array}$ \\
\hline Manajemen & $\begin{array}{l}\text { - } \text { Manajemen } \\
\text { Produksi } \\
\text { - Manajemen } \\
\text { Pemasaran } \\
\text { - Manajemen } \\
\text { SDM } \\
\text { - Manajemen } \\
\text { Keuangan }\end{array}$ & $\begin{array}{l}\text { - Ceramah } \\
\text { - Praktik } \\
\text { - Diskusi }\end{array}$ & \\
\hline
\end{tabular}

B. Metode Pengabdian

Participatory Learning Methods, yaitu pembelajaran secara partisipatif, aktualisasi pengetahuan yang dimiliki sebelumnya dipadukan dengan pengetahuanpengetahuan baru pada hakikatnya akan bermanfaat dalam meningkatkan kualitas sumber daya manusia dan kesejahteraan masyarakat (Adimiharja, 2003).
C. Metode Pengumpulan Data

1. Metode Observasi

Metode observasi merupakan metode pengumpulan data dengan cara melakukan pengamatan langsung terhadap objek penelitian. Metode ini dilakukan dengan mengamati secara langsung kegiatan Karawitan Bapak-Bapak di Balai Desa Sendangsari, Karawitan Remaja di Balai Desa Sendangsari, Karawitan Ibu PKK Desa Sendangsari, kegiatan tim SID dan remaja-remaja komunitas fotografi dan videografi di Desa Sendangsari, dan kelompok usaha kerajinan sabut kelapa di Desa 
Sendangsari, serta kelompok usaha kerajinan kulit di Desa Sendangsari.

\section{Metode Wawancara}

Metode wawancara merupakan metode pengumpulan data melalui tatap muka secara langsung dengan pihak-pihak tertentu, dalam hal ini adalah Camat Pengasih, Kepala Desa Sendangari, Carik Sedangsari, para Kepala Dusun, tim SID, pelaku kegiatan karawitan, komunitas fotografi, pelaku usaha kerajinan kulit, dan kerajinan sabut kelapa.

Dengan adanya wawancara diharapkan bisa mendapatkan informasi yang lengkap tentang seluruh kegiatan tersebut dan mengantisipasi tumpang tindih pembinaan, seperti hasil temuan Kuncoro (2000), bahwa pembinaan UKM yang dilakukan oleh berbagai instansi (pemerintah \& nonpemerintah) sering tumpang tindih karena adanya perbedaan persepsi pada masing-masing instansi yang berakibat ketidakefektifan arah pembinaan dan tidak adanya indikator keberhasilan yang seragam.

\section{HASIL PEMBINAAN}

Hasil kegiatan P3Wilsen di Desa Sendangsari ini di antaranya:

1. peningkatan keterampilan peserta pelatihan kriya kulit teknik, dan pembuatan produk, misalnya suvenir khas daerah setempat;

2. peningkatan keterampilan peserta pelatihan dokumentasi berbasis fotografi dan videografi; dan

3. peningkatan keterampilan teknik dalam menabuh gamelan yang baik dan benar.

Hasil pembinaan ini dapat terlaksana dengan baik karena adanya antusiasme dan partisipasi aktif dari pesertanya dan metode pelatihan yang dirancang disesuaikan dengan kebutuhan dan sumber daya yang ada. Metode pelatihan telah mengikuti temuan Cassell, Nadin, Gray, \& Clegg (2002) bahwa pelatihan di UKM lebih efektif ketika difokuskan pada kesesuaiannya dengan kebutuhan atau tailor made. 


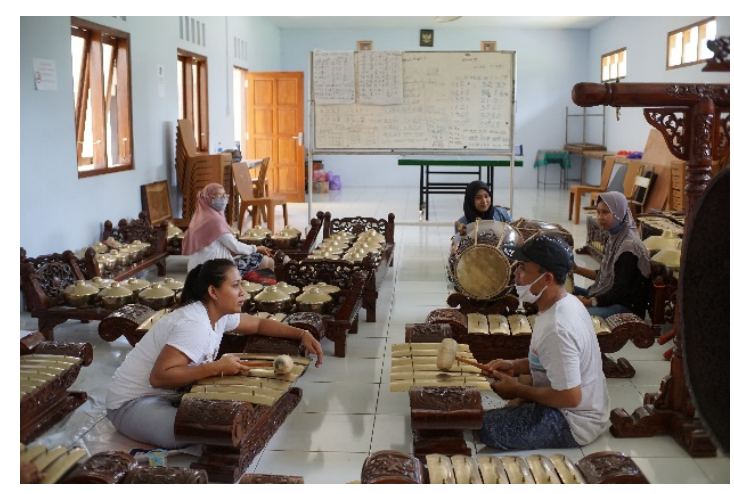

Gambar 1 Pelatihan Karawitan

(Dokumen penulis, 5 November 2020)

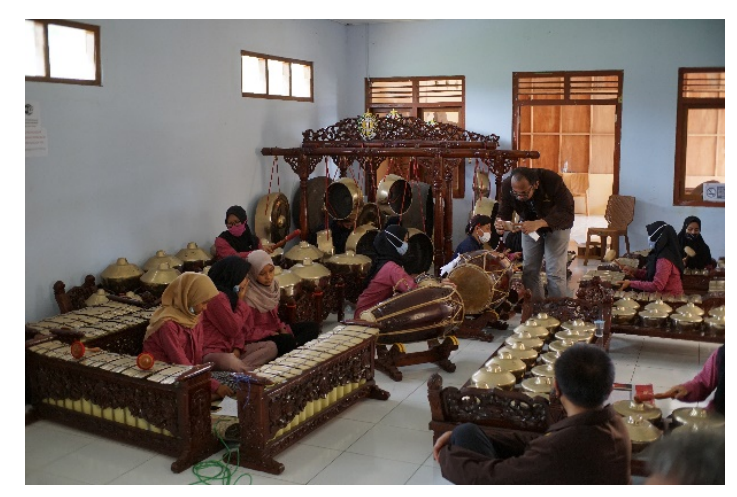

Gambar 2 Persiapan Pentas Seni Karawitan Hasil Pelatihan (Dokumen penulis, 21 November 2020)

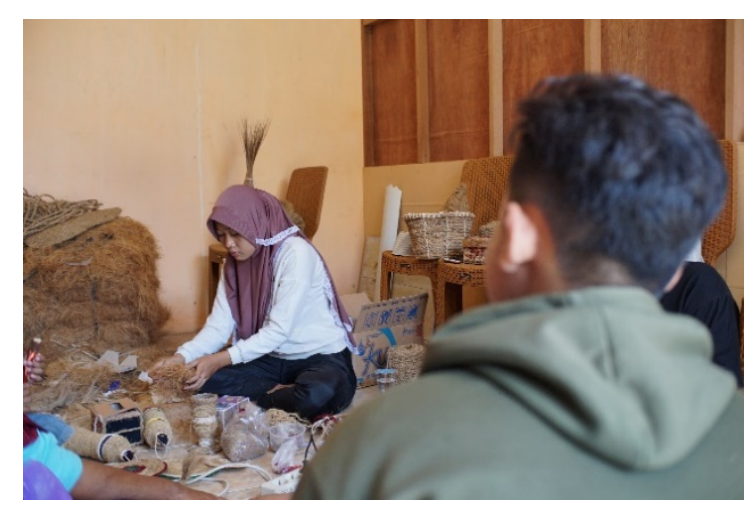

Gambar 3 Pelatihan Kerajinan Sabut Kelapa (Dokumentasi penulis, November 2020) 


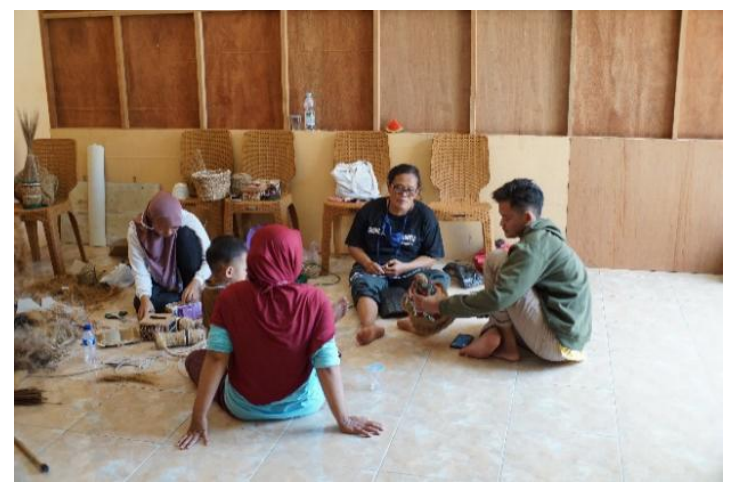

Gambar 4 Pelatihan Kerajinan Sabut Kelapa (Dokumentasi penulis, November 2020)

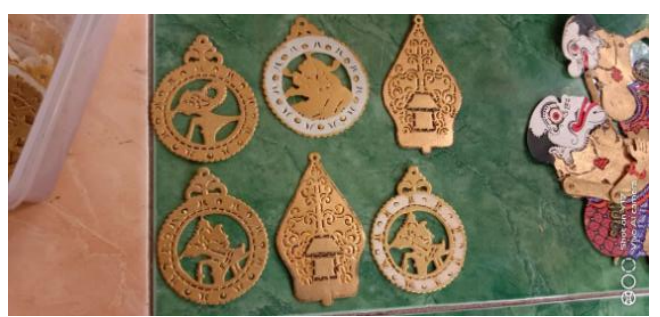

Gambar 5 Pemberian Materi Fotografi dan Videografi (Dokumentasi penulis, November 2020)

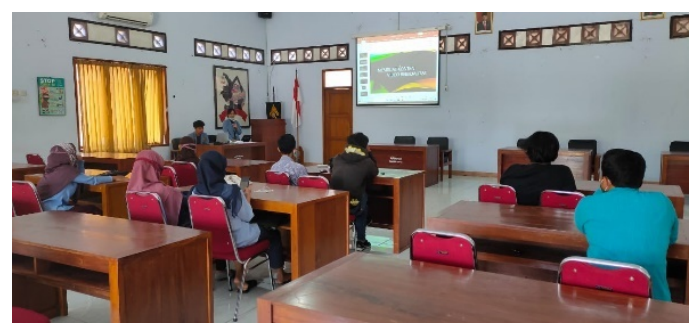

Gambar 6 Hasil Pelatihan Pengrajin Tatah Kulit Sungging (Dokumentasi penulis, 21 November 2020) 


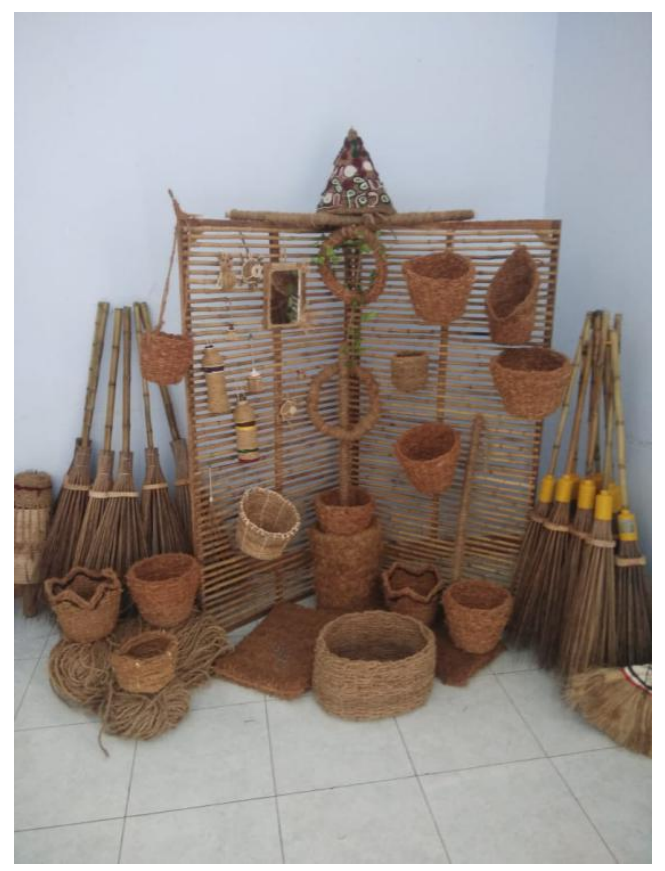

Gambar 7 Hasil Pelatihan Kerajinan Sabut Kelapa

(Dokumen penulis, 21 November 2020)

\section{KESIMPULAN}

Salah satu program pada Lembaga Pengabdian Masyarakat (LPM) ISI Yogyakarta adalah Program Pembinaan dan Pengembangan Wilayah Seni (P3Wilsen) dalam aktivitasnya di Desa Sendangsari, Kecamatan Pengasih, Kabupaten Kulonprogo pada SeptemberNovember 2020 berjalan lancar dan memuaskan. Keberhasilan yang dicapai itu tidak dapat lepas dari usaha tim P3Wilsen dalam pelatihan di Balai Desa Sendangsari. Sebagai puncaknya, hasil dari pelatihan ditampilkan bersama dalam rangka penutupan dan sekaligus pelepasan mahasiswa yang terlibat. Namun, perlu diketahui bahwa keberhasilan P3Wilsen yang telah dijalankan tersebut tidak dapat dipisahkan atas terjalinnya kerjasama yang baik antara LPM ISI Yogyakarta dan Desa Sendangsari, Kecamatan Pengasih, Kabupaten Kulonprogo, DIY.

\section{SARAN}

Berdasarkan proses pelaksanaan hingga berakhirnya kegiatan program P3Wilsen yang melibatkan berbagai seni pada kelompokkelompok seni di Desa Sendangsari, Kecamatan Pengasih, Kabupaten Kulonprogo, DIY tersebut, tentu saja ada kekurangankekurangan yang terjadi. Adapun efek dari program tersebut, kini komunitas seni dan kelompok usaha makin berkembang. Dengan demikian, sangat diharapkan sangat kritik dan saran yang membangun dari pembaca sekalian.

\section{UCAPAN TERIMA KASIH}

Program P3Wilsen di Desa Sendangsari, Kecamatan Pengasih, Kabupaten Kulon Progo telah terlaksana dengan lancar dan baik. Hal ini berkat dukungan dan bantuan dari berbagai pihak. Oleh karena itu, kami mengucapkan terima kasih kepada: (1) LPPM ISI Yogyakarta, (2) Kecamatan Pengasih, (3) Pemerintah Desa Sendangsari, (4) mahasiswa 
P3Wilsen, dan (5) seluruh warga Sendangsari yang telah mengikuti kegiatan P3Wilsen.

\section{DAFTAR PUSTAKA}

Adimiharja, Kusnaka. (2003). PRA: Partisipatory Research Appraisal dalam Pelaksanaan Pengabdian kepada Masyarakat. Bandung.

Cassell, C., Nadin, S., Gray, M., \& Clegg, C. (2002). Exploring Human Resource
Management Practices in Small and Medium Sized Enterprises.

Kuncoro, M. (2000). Usaha Kecil di Indonesia: Profil, Masalah dan Strategi Pemberdayaan.

Sjaifudian, H., Haryadi, D., \& Maspiyati. (1995). Strategi dan Agenda Pengembangan Usaha Kecil. Bandung: Akatiga. 
